\title{
EARLY MOTHER-INFANT INTERACTION AFTER DELIVERY: A NATURALISTIC STUDY
}

\author{
Tania Kiehl Lucci'1, Renata Pereira Defelipe', Nara Côrtes Andrade², Vinicius \\ Frayze David', Emma Otta ${ }^{1}$
}

${ }^{1}$ Institute of Psychology, Experimental Psychology, University of Sao Paulo, Brazil

2Institute of Psychology, Catholic University of Salvador, Brazil

tanialucci@usp.br

\begin{abstract}
Although there is a vast literature on early mother-infant interaction, there are fewer studies that investigate mother-infant behaviors immediately after delivery in natural conditions. Our aim was to investigate early mother-infant interaction as a function of mothers' emotional states, infants' sex and weight, and hospital procedures. Newborns were filmed when placed naked on their mother's chests $(N=60)$. Maternal (caress) and infant behaviors (crying and calming down) were coded every 10 seconds using Interact software. Mothers reported their emotional state, 1-2 days after delivery, using a five-point Likert scale, and answered the Edinburgh Postnatal Scale at 4-16 weeks postpartum. Multiple Ordinal Regressions considered maternal emotional conditions (emotional state and postpartum depression), infant's sex and weight, and hospital procedures (childbirth type and skin-to-skin contact) as independent variables, and the frequency of maternal and infant behaviors as outcome variables. Infants from mothers feeling 'great' and not at risk for depression were less likely to cry as compared to their counterparts. Mothers were more likely to caress their sons than their daughters. Boys were more likely to cry and less likely to calm than girls. Newborn weight and skin-to-skin contact were positively associated with infants' calming down. Infants cried more after normal delivery than after instrumental delivery. Our results showed that mother-infant early interactions are influenced by multiple levels and suggest hormonal influences during pregnancy.
\end{abstract}

Keywords: mother-infant, behavior, newborn, emotional state, sex differences, skin-to-skin contact, childbirth type.

* Paper presented at XXIV Biennial Conference of Human Ethology 2018, in Santiago, Chile. 


\section{INTRODUCTION}

\section{Prenatal development}

Infants demonstrate a capacity to stimulate social interactions from a very early age (Ribeiro, Bussab \& Otta, 2004). This ability for social interaction, present in newborns, suggests that these behaviors were selected through evolution by increasing the chance of survival of these individuals, who are born totally dependent on the availability of care by an adult.

Concerning human prenatal development, it is known that fetuses are active and develop in a stimulating environment. At the moment of delivery, newborns have already had present an important set of experiences, accumulated during the period of intrauterine development, especially tactile and auditory experiences from the rhythms of the mother's body, and they have been affected by other factors including maternal diet, and the hormones released by her. At only 21 weeks of gestation, they show an increase in movements of arms, head, and mouth in response to maternal touch of the womb and a decrease in movements of head and arms in reaction to the mother's voice (Marx \& Nagy, 2015).

\section{Touch and affect}

According to Feldman, Singer and Zagoory (2010) physical contact and parental touch have the effect of organizing the behavior and physiology of newborns suggesting that it may have significant survival value. Research with rats has shown that tactile stimulation and breastfeeding increase a resilience response to stress associated with hormonal regulation in neonatal rats. Michael Meaney was one of the first researchers to identify the importance of maternal care in altering the expression of genes that regulate behavioral and neuroendocrine responses associated with stress in rats. Lower frequency of maternal care behaviors in rats was associated with hormonal alteration that resulted in an increase in the physiological response to stress, making the individuals more frightened and defensive (Liu et al., 1997; Meaney, 2010). In humans, caressing and comforting is of special importance in promoting a sense of being valued. This influences the child's emotional and social development and serves as pre-linguistic communication of affect (Anisfeld, Casper, Nozyce, Cunningham, 1990).

\section{Maternal emotional state and their effects on early mother-infant interaction}

Researchers have been investigating the effect of maternal characteristics measured during gestation, such as depression and anxiety on postnatal newborn's behavior (Hepper, 2015), and the analysis of fetal behavior indicates differences in physiological and behavioral responses. Compared to fetuses of non-depressed mothers, higher basal heart rate was observed in depressed mothers' fetuses, as well as a higher level of motor activity during the second and third trimester of pregnancy, and decreased behavioral response at the end of gestation (Dieter, Emory, Johnson \& Raynor, 2008; Allister, Lester, Carr \& Liu, 2001).

The mechanisms by which maternal emotional status may interfere with fetal development during gestation are not yet understood. Among the most studied 
hypotheses, derived from results with nonhuman animals, is that stress or anxiety increases the transmission of maternal cortisol through the placenta (O'Donnell \& Glover, 2008; Graignic-Philippe, Dayan, Chokron, Jacquet \&Tordjman, 2014).

\section{Infant's sex and weight and their effects on early mother-infant interaction}

Sex and birth weight are likely to be relevant variables affecting early mother-baby interaction and involved in the regulation of maternal behavior. Mother-father-infant interaction 6-48 hour postpartum has indicated that both mothers and fathers affectionately touched their sons more than their daughters (Parke; 1972). Davis and Emory (1995) found different reactions among 36 infants with a mean age of 31 hours on a medium-stress medical procedure. Male newborns had an increase in cortisol concentration compared to females. The review by Campbell and Eaton (1999), considering 46 studies with infants between zero and twelve months, shows that males have more motor activity compared to females. Under the 'still-face' paradigm five-six month old boys exhibited a higher level of activity and excitement and a greater expression of negative emotions than girls (Weinberg, Tronick, Cohn \& Olson, 1999). The present study is the first research, as far as we know, that observes differences in neonate behaviors as a function of sex in the first minutes of life.

There are many studies showing the importance of maternal contact (skin-to-skin and gentle touch) to the development of low birth weight and preterm infants (Weiss, Wilson \& Morrison, 2004, Boundy et al, 2016). However, there are no studies, as far as we know, describing how the frequency of mothers touching their infants is associated with their weight.

\section{Hospital procedures and their effects on early mother-infant interaction}

Skin-to-skin contact is recommended to low birth newborns in order to promote greater physiological stability, better temperature and oxygen regulation, maturation of the autonomic nervous system and circadian rhythm (Feldman \& Eidelman, 2003), increased stability in sleep patterns, and also to stimulate breastfeeding (Boundy et al, 2016). Higher vocalization of the parents towards their newborns and lower infant body activity were observed when the dyad was in skin-to-skin contact (Velandia, Matthisen, Uvnäs-Moberg \& Nissen, 2010). Recent evidence supports the recommendation of skinto-skin contact for all healthy, full-term babies and not only for those born with low birth weight (Cleveland et al., 2017).

There is no consensus in the literature regarding the influence of type of delivery (vaginal delivery and cesarean section) on the quality of mother-baby interaction. Considering vaginal deliveries there is also the instrumental delivery or forceps delivery, which are accomplished with the help of instruments (vacuum or forceps). Cesarean delivery has been associated with a lower frequency of positive reactions to babies and less interaction between mothers and newborns as compared to mothers who had vaginal deliveries (DiMatteo et al., 1996; Rowe-Murray \& Fischer, 2001). However, others studies did not observe these differences according to type of delivery (Gottlieb \& Barrett, 1986; Siddiqui \& Hägglöf, 2000). 
Despite the importance of mother-infant interactions to early development, few studies have analyzed direct observational data of mothers and their newborns immediately after birth (Widström et al., 2011; Figueiredo, Costa, Pacheco \& Pais, 2009, Fleming, Ruble, Flett \& Shaul, 1988; Parke, 1972). The present study involves descriptive data of maternal and infant behaviors in the naturalistic setting of the delivery room immediately after birth. Our aim was to check the impact of mothers' emotional conditions (such as a mother's emotional state and mother who would be subsequently diagnosed as experiencing postpartum depression), newborn sex and weight, and hospital procedures (childbirth types, skin-to-skin contact) on mother-infant interaction in the immediate postpartum period, more specifically on the newborn's behavior (crying and calming down behavior), and the mother's affectionate touch.

\section{Hypotheses}

We had three sets of hypotheses regarding maternal and infant sex and weight, and hospital procedures. Concerning maternal characteristics, mothers with negative emotions would caress their infants less, while their infants would cry more and calm less. In relation to infant physical characteristics, male infants would cry more and calm less than female infants, while they would receive more maternal touch. Infants with lower weight would cry more, calm less, and receive more maternal touch. Regarding hospital procedures after birth, skin-to-skin contact would enhance infants' calming and maternal touch and would decrease infants' crying. Normal delivery, compared to instrumental delivery, would enhance infants' crying and decrease infants' calming and maternal touch. 


\section{METHODS}

\section{Participants}

A total of 60 pregnant women who gave birth at the University Hospital between the years of 2006-2008 and agreed to participate. The research was approved by the Research Ethics Committee (CAAE: 0051.0.198.000-06).

\section{Procedures}

With the consent of mothers and obstetricians, nurses recorded the moment of birth and immediate postpartum behaviour, when the newborn was positioned on the mother's chest. Recording of mother-infant interaction continued while the umbilical cord was cut, the placenta expelled, and continued until the newborn was taken by the nurses. During recording, mothers remained lying on the hospital bed in the delivery room with the babies on their chests.

\section{Behavior coding}

The behavior categories were defined based on previous mother-infant interaction studies (Parke, Grossman \& Tinsley, 1981; Fleming, Flett, Ruble \& Shaul, 1988). Behaviors were coded using Interact software, and $20 \%$ of the videos were coded by two researchers blind to participants' identities and their emotional conditions with $>0.63$ agreement as measured by Cohen's kappa (Viera \& Garrett, 2005). Coding started when the newborn was placed on a woman's chest. Videos had different durations with a mean of two minutes and ten seconds. Percentages of time spent in the performance of each behavior were transformed into ordinal categories, based on quartile distribution: $0-25 \%$; $26-50 \%$; $51-75 \%$ and $>75 \%$.

Table 1: Ethogram: observed behaviors.

\begin{tabular}{|c|c|}
\hline Infant cry & infant's shrill and uninterrupted cry, with open mouth and usually with eyes closed \\
\hline $\begin{array}{l}\text { Infant calming } \\
\text { down }\end{array}$ & $\begin{array}{l}\text { the behavior is coded considering the previous scene. Newborn is considered to be } \\
\text { calming down as it decreases the intensity of crying and body movement }\end{array}$ \\
\hline $\begin{array}{l}\text { Mother's caress } \\
\text { touch }\end{array}$ & mother's gently touch their infant's face or body, cradle in a gentle way \\
\hline
\end{tabular}




\section{Instruments}

One to two days after delivery mothers were asked how they were feeling in a five-point scale formulated for the present study. Edinburgh Postpartum Depression Scale (EDPE) was administered to mothers (Cox, Holden and Sagovsky,1 987) to evaluate the incidence of postpartum depression (PPD) (scores> 12) four to sixteen weeks postpartum (validated in Brazil by Santos et. al.,1995). Information on delivery conditions and newborn's information was obtained from the medical records of the hospital.

\section{Data analysis}

Three Multiple Ordinal Regressions were performed: each of them considered one observed ordinal variable (crying behavior, mothers' caressing and calming behaviors) with a set of six independent variables: newborn's sex and weight; hospital procedures (childbirth type and skin-to-skin contact), and mother's emotional variables (emotional state, asked 1-2 days after delivery, and postpartum depression, measured 4 to 16 weeks after delivery).

\section{RESULTS}

\section{Descriptive analyses}

Mothers' mean age was 24 years $( \pm 6)$ and fathers' 28 years $( \pm 7)$, with an average of 9 years of education $( \pm 2)$. Most mothers lived with the infant's father $(\mathrm{N}=48,80 \%)$ and already had at least one child $(\mathrm{N}=32,53 \%)$. Women had on average a 39-week gestation $( \pm 1)$ and $80 \%$ of them $(\mathrm{N}=48)$ had an accompanist during delivery, usually their mothers or the father of the child. Only three women had a cesarean section and were not considered in the analysis due to the small sample. Among those who underwent vaginal delivery, 17 (29\%) had instrumental labor. Half of the infants were female $(\mathrm{N}=$ $33,56 \%)$, all newborns were of normal weight (>2.500kgs), and had an APGAR score between 9 and 10 evaluated at the tenth minute of life, thus indicating good health.

\section{Infant cry}

Ordinal Regression Analysis, considering infant crying as a dependent variable and mother's emotional state, postpartum depression, sex, weight, skin-to-skin contact, and childbirth type as independent variables, was a significant model $\left(\mathrm{X}^{2}(7)=19.345, \mathrm{p}<0.01\right.$, $\mathrm{R}^{2}=41.2$ ) (Table 2). 
Table 2: Odds ratio and interval confidence of the multiple ordinal regressions considering infant crying.

\begin{tabular}{|c|c|c|c|c|c|}
\hline & & Wald & p-value & OR & $95 \% \mathrm{CI}$ \\
\hline \multirow{5}{*}{$\begin{array}{l}\text { Mother's } \\
\text { emotional state }\end{array}$} & Emotional: bad/regular & 0.115 & 0.735 & 0.685 & $0.076-6.138$ \\
\hline & Emotional: good & 3.803 & 0.051 & 5.92 & $0.991-35.370$ \\
\hline & Emotional: great & & & 1.00 & \\
\hline & Not depressed & 6.406 & 0.011 & 0.103 & $0.018-0.599$ \\
\hline & Postpartum depression & & & 1.00 & \\
\hline \multirow{3}{*}{$\begin{array}{l}\text { Infant's } \\
\text { characteristics }\end{array}$} & Birth weight & 5.737 & 0.017 & 0.997 & $0.995-1.000$ \\
\hline & Male & 7.978 & 0.005 & 8.722 & $1.940-39.201$ \\
\hline & Female & & & 1.00 & \\
\hline \multirow{4}{*}{$\begin{array}{l}\text { Medical } \\
\text { procedures }\end{array}$} & Normal labor & 4.705 & 0.03 & 5.335 & $1.175-24.221$ \\
\hline & Instrumental labor & & & 1.00 & \\
\hline & Skin to skin & 1.302 & 0.254 & 2.345 & $0.542-10.135$ \\
\hline & No skin to skin & & & 1.00 & \\
\hline
\end{tabular}

Mother's emotional state and postpartum depression were significant predictors of infant crying behavior. Infants whose mothers were not at risk for postpartum depression were less likely to cry $(\mathrm{OR}=0.103 ; 95 \% \mathrm{CI} ; 0.018-0.599)$ as compared to infants of mothers at risk for postpartum depression. Regarding mother's emotional state, infants of women who answered that they were feeling 'good' were more likely to cry as compared to those who answered that they were feeling 'great' (OR=5.920; 95\% CI; 0.991-35.370).

In this same model, infant sex and weight were also significant. Boys were more likely to cry immediately after birth as compared to girls ( $\mathrm{OR}=8.72$; 95\% CI 1.94-39.2). An increase in weight (grams) was associated with a decrease in the odds of crying (O.R= 0.997 95\% CI 0.995-1.000).

Childbirth type was a significant variable when comparing crying behavior between infants. Only three mothers delivered by cesarean section and were not considered in the analysis. Children of mothers in normal delivery were more likely to cry when compared to mothers in instrumental delivery $(\mathrm{O} . \mathrm{R}=5.335$; 95\% CI, 1.175-24.221). Skin-to-skin contact immediately after delivery was not a significant variable to predict infant crying behavior (O.R=2.345; 95\% CI 0.542-10.135). 


\section{Mother caress}

The second ordinal regression analysis considering mother's caress as a dependent variable and the same variables in the previous model (mother's emotional state and postpartum depression, infant's sex and weight, skin-to-skin contact and childbirth type) as independent variables showed that the model was significant $\left(\mathrm{X}^{2}=18.298 ; \mathrm{p}<0.05\right.$; $\left.\mathrm{R}^{2}=35.7\right)$. The only variable that predicted mothers' caress was the infant's sex. Mothers were four times more likely to caress their sons as compared to their daughters (O.R=3.918; 95\% CI 1.083-14.177) (Table 3).

Table 3: Odds ratio and interval confidence of the multiple ordinal regressions considering mother's caress.

\begin{tabular}{|c|c|c|c|c|c|}
\hline & & Wald & p-value & OR & $95 \% \mathrm{CI}$ \\
\hline \multirow{5}{*}{$\begin{array}{l}\text { Mother's } \\
\text { emotional state }\end{array}$} & Emotional: bad/regular & 2.014 & 0.156 & 0.214 & $0.026-1.799$ \\
\hline & Emotional: good & 1.707 & 0.191 & 2.765 & $0.601-12.718$ \\
\hline & Emotional: great & & & 1.000 & \\
\hline & Not depressed & 0.169 & 0.681 & 1.323 & $0.348-5.026$ \\
\hline & Postpartum depression & & & 1.000 & \\
\hline \multirow{3}{*}{$\begin{array}{l}\text { Infant's } \\
\text { characteristics }\end{array}$} & Birth weight & 0.047 & 0.829 & 1.000 & $0.998-1.002$ \\
\hline & Male & 4.333 & 0.037 & 3.918 & $1.083-14.177$ \\
\hline & Female & & & 1.000 & \\
\hline \multirow{4}{*}{$\begin{array}{l}\text { Medical } \\
\text { procedures }\end{array}$} & Normal labor & 1.943 & 0.163 & 0.405 & $0.113-1.444$ \\
\hline & Instrumental labor & & & 1.000 & \\
\hline & Skin to skin & 2.65 & 0.104 & 0.361 & $0.106-1.231$ \\
\hline & No skin to skin & & & 1.000 & \\
\hline
\end{tabular}

\section{Calming behavior}

Ordinal Regression Analysis considering infant's calming behavior as a dependent variable and mother's emotional state and postpartum depression, the infant's sex and weight, and hospital procedures as skin-to-skin contact and childbirth type as independent variables, was significant with $54 \%$ of the variance being explained by the model $\left(\mathrm{X}^{2}=29.37 ; \mathrm{p}<0.001 ; \mathrm{R}^{2}=54.6\right)$ (Table 4). 
Table 4: Odds ratio and interval confidence of the multiple ordinal regressions considering infant's calming.

\begin{tabular}{|c|c|c|c|c|c|}
\hline & & Wald & p-value & OR & $95 \% \mathrm{CI}$ \\
\hline \multirow{5}{*}{$\begin{array}{l}\text { Mother's } \\
\text { emotional state }\end{array}$} & Emotional: bad/regular & 0.797 & 0.372 & 0.337 & $0.031-3.667$ \\
\hline & Emotional: good & 7.964 & 0.005 & 0.053 & $0.007-0.407$ \\
\hline & Emotional: great & & & 1.000 & \\
\hline & Not depressed & 1.026 & 0.311 & 2.307 & $0.458-11.634$ \\
\hline & Postpartum depression & & & 1.000 & \\
\hline \multirow{3}{*}{$\begin{array}{l}\text { Infant's } \\
\text { characteristics }\end{array}$} & Birth weight & 12.784 & 0.000 & 1.004 & $1.002-1.007$ \\
\hline & Male & 7.479 & 0.006 & 0.099 & $0.019-0.519$ \\
\hline & Female & & & 1.000 & \\
\hline \multirow{4}{*}{$\begin{array}{l}\text { Medical } \\
\text { procedures }\end{array}$} & Normal labor & 5.406 & 0.020 & 0.143 & $0.028-0.737$ \\
\hline & Instrumental labor & & & 1.000 & \\
\hline & Skin to skin & 3.731 & 0.053 & 0.198 & $0.038-1.024$ \\
\hline & No skin to skin & & & 1.000 & \\
\hline
\end{tabular}

Mother's emotional state was a significant predictor of calming behavior. Infants whose mothers answered they were feeling 'good' were less likely to calm as compared to those who answered they were feeling 'great' ( $\mathrm{OR}=0.053$; 95\% CI $0.007-0.407)$. However, there was no group effect on calming behavior among women who answered they were feeling 'good' as compared to those who said they feeling 'bad'. Postpartum depression was not a predictor of child's calming behavior.

Sex had a significant effect on calming behavior; boys were less likely to calm as compared to girls $(\mathrm{OR}=0.099 ; 95 \% \mathrm{CI} 0.019-0.519)$. Birth weight was also significant. An increase in weight (expressed in grams) was associated with an increase in the odds of calming down (OR=1.004; 95\% CI 1.002-1.007). 


\section{DISCUSSION}

Our aim was to investigate if mother's emotional state, infant's sex and weight and hospital procedures were associated with the frequency of infant and mother behaviors immediately after birth. The results showed that infants of mothers who were at risk for PPD were more likely to cry for a longer time. There are two possible explanations: women already showed signs of depression during pregnancy and this predicted higher frequency of cry at birth, or mothers of infants that cried more often were more susceptible to develop postpartum depression. Studies indicate results in both directions. Sons of mothers with depression had a higher frequency of crying and difficulty in being calm in the first days of life (Ottinger \& Simons, 1964; Zuckerman et al., 1990), whilst a study showed that neonatal irritability was predictive of maternal PPD (Murray et al., 1996). Furthermore, maternal emotional state measured by the answers to a question (women were asked while still in the maternity), also showed that children of mothers who reported being emotionally well had a lower chance of crying and were more likely to calm; so our results support the first explanation. However we didn't find difference on crying duration between newborns of mothers who were 'feeling bad' $(\mathrm{N}=07)$ and those who were 'feeling great' $(\mathrm{N}=39)$. One possible explanation is our low sample of mothers that informed us that were feeling "bad". It could be that mothers were embarrassed to report their negative emotion at a period considered by society to be 'special' and tended to minimize reporting they were 'well'. Since newborn behaviors were observed within the first few minutes after delivery and, therefore, babies had not had the opportunity to interact with their mothers outside the womb, it is more reasonable to assume that the impact of maternal emotional state occurred during gestation. Thus, Field et al. (2014) report that newborns from mothers at risk for depression present several dysfunctions due to maternal biochemical exchanges during pregnancy, possibly through hormonal transmissions. In a previous study, part of this same project, newborns of mothers at risk for postpartum depression showed a higher concentration of salivary cortisol two days after delivery as compared to newborns of mothers not at risk for depression with a moderate effect size, although the effect was marginally significant (Lucci et al., 2016).

Infants' sex and weight showed a potential to influence the behavior of both the newborn and the mother. Mothers were more likely to affectionately touch their newborn sons; however, they were also more likely to cry and less likely to calm and therefore, maternal behavior may have been modulated by the behavior of newborns. Sex differences in frequency of behavior have been discussed for decades, and considering only studies of early development, males showed more motor activity as compared to females (0-12 months) (Campbell \& Eaton, 1999) and a higher level of activity and excitement, and greater expression of negative emotions in the 'still-face' paradigm as compared to females presenting higher language skills and inhibitory control (Weinberg et al, 1999). The observation of behavior in the immediate postpartum can contribute to enrich the debate insofar as it offers elements to the study of newborns that are not under the influence of the socialization experiences external to the mother's womb. The hypothesis of sex differences in infant behavioral frequency is based on the idea that the 
brain is influenced by hormones during fetal development, leading to differences in brain structures (Velandia, Uvnäs-Moberg \& Nissen, 2011)

Considering newborns' characteristics, individuals with greater weight were less likely to cry and more likely to calm. In the present study, our sample was composed only by normal birth weight $(>2500 \mathrm{~g})$ and therefore it was not possible to determine the influence of low birth weight conditions on the frequency of crying behavior. We suggest future studies focusing on this population at higher risk to assess a potential impairment of the frequency of newborn crying in early development. Our results on infants' characteristics, such as sex and weight in the period immediately after birth, may indicate that individuals play an active role since the first moments after birth, and perhaps even before birth (Gotlieb, 2007).

The present study corroborates previous findings regarding the importance of skin-to-skin contact to calm newborn and supports the recommendation of this technique for all healthy term babies and not only for low birth weight infants (Cleveland et al., 2017). According to Feldman (2010) physical contact and initial touch helps newborn's to organize their behavior and physiology and promotes mother-infant bond. Our results are in agreement with the study of Velandia, Matthisen, Uvnäs-Moberg and Nissen (2010), in that skin-to-skin contact promotes lower infant activity and higher frequency of parental vocalization towards the newborn.

Newborns from normal deliveries were more likely to cry as compared to those from instrumental deliveries. In the present study cesarean sections were not considered due to the low sample number. Both normal birth and instrumental labor require the physical effort of infants to get out of the womb, but it is known that instrumental delivery is performed to assist the expulsion of the baby in cases of risk or when there is difficulty in passing through the vagina. It may be assumed that newborns from instrumental labors are more likely to calm by physical fatigue due to a more difficult delivery. Other possible hypothesis is the influence of stronger anesthesia, used more frequently in instrumental delivery, on the odds of calming-down behavior.

It is interesting to note that maternal behavior towards the baby was not impaired due to the maternal emotional state or the risk of developing signs of depression. Mothers affectionately touched their infants regardless of how they felt emotionally in the immediate postpartum period. Perhaps these results explain the complexity of the effects of postpartum depression on early mother-infant interaction and infant development (Grace, Evindar \& Stewart, 2003). In the Project to which this research is linked, postpartum depression did not affect the maternal emotional availability evaluated four months after childbirth (Fonseca, Silva \& Otta, 2010); however, there was less vocalization aimed at babies (4 months) among depressed mothers, especially when they had other children (Morais, Lucci \& Otta, 2013).

In conclusion, our study showed that mother-infant early interactions are influenced by multiple levels such as a mother's emotional state, infants' sex and weight, and hospital procedures. As mother-infant interaction was evaluated considering the first minutes outside the mother's womb, the results suggest that infants' behaviors were influenced by their mother's emotional condition and infants' sex presumably by hormonal influences during pregnancy. Skin-to-skin contact also had an important 
influence on infant calming behavior, and our result may contribute to enhance this care by medical staff shortly after birth.

\section{Future directions}

In this study we did not evaluate differences in behavior frequencies between normal delivery and cesarean section. Other interesting aspect is the assessment of how frequently fathers were present at the delivery room in order to study if the quality of marital interaction may affect the frequency of behaviors directed at infants.

\section{ACKNOWLEDGMENTS}

We are grateful to all participants who shared with us important moments of their lives and to all students and nurses who directly participated in data collection.

\section{REFERENCES}

Allister, L., Lester, B. M., Carr, S., \& Liu, J. (2001). The effects of maternal depression on fetal heart rate response to vibroacoustic stimulation. Developmental Neuropsychology, 20(3), 639-651. DOI

Anisfeld, E., Casper, V., Nozyce, M., \& Cunningham, N. (1990). Does infant carrying promote attachment? An experimental study of the effects of increased physical contact on the development of attachment. Child Development, 61(5), 1617-1627. DOI

Boundy, E. O., Dastjerdi, R., Spiegelman, D., Fawzi, W. W., Missmer, S. A., Lieberman, E., ... \& Chan, G. J. (2016). Kangaroo mother care and neonatal outcomes: a meta-analysis. Pediatrics, 137(1), e20152238. DOI

Campbell, D. W.,\& Eaton, W. (1999). Sex Differences in the Activity Level of Infants. Infant and Child Development, 8(1), 1-17. DOI

Cleveland, L., Hill, C. M., Pulse, W. S., DiCioccio, H. C., Field, T., \& White-Traut, R. (2017). Systematic review of skin-to-skin care for full-term, healthy newborns. Journal of Obstetric, Gynecologic \& Neonatal Nursing, 46(6), 857-869. DOI

Davis, M., \& Emory, E. (1995). Sex differences in neonatal stress reactivity. Child Development, 66(1), 14-27. DOI

Dieter, J. N., Emory, E. K., Johnson, K. C., \& Raynor, B. D. (2008). Maternal depression and anxiety effects on the human fetus: preliminary findings and clinical implications. Infant Mental Health Journal, 29(5), 420-441. DOI

DiMatteo, M. R., Morton, S. C., Lepper, H. S., Damush, T. M., Carney, M. F., Pearson, M., \& Kahn, K. L. (1996). Cesarean childbirth and psychosocial outcomes: A meta-analysis. Health Psychology, 15(4), 303. DOI 
Feldman, R., \& Eidelman, A. I. (2003). Skin-to-skin contact (Kangaroo Care) accelerates autonomic and neurobehavioural maturation in preterm infants. Developmental Medicine \& Child Neurology, 45(4), 274-281. DOI

Feldman, R., Singer, M., \& Zagoory, O. (2010). Touch attenuates infants' physiological reactivity to stress. Developmental Science, 13(2), 271-278. DOI

Field, T. M. (Ed.). (2014). Touch in early development. Psychology Press. DOI

Figueiredo, B., Costa, R., Pacheco, A., \& Pais, A. (2009). Mother-to-infant emotional involvement at birth. Maternal and Child Health Journal, 13(4), 539-549. DOI

Fleming, A. S., Ruble, D. N., Flett, G. L., \& Shaul, D. L. (1988). Postpartum adjustment in firsttime mothers: Relations between mood, maternal attitudes, and mother-infant interactions. Developmental Psychology, 24(1), 71-81. DOI

Fonseca, V. R. J., Silva, G. A. D., \& Otta, E. (2010). Relação entre depressão pós-parto e disponibilidade emocional materna. Cadernos de saúde pública, 26(4), 738-746. DOI

Grace, S. L., Evindar, A., \& Stewart, D. E. (2003). The effect of postpartum depression on child cognitive development and behavior: a review and critical analysis of the literature. Archives of Women's Mental Health, 6(4), 263-274. DOI

Gottlieb, S. E.,\& Barrett, D. E. (1986). Effects of unanticipated cesarean section on mothers, infants, and their interaction in the first month of life. Journal of Developmental and Behavioral Pediatrics. DOI

Gottlieb, G. (2007). Probabilistic epigenesis. Developmental Science, 10(1), 1-11. DOI

Graignic-Philippe, R., Dayan, J., Chokron, S., Jacquet, A. Y., \& Tordjman, S. (2014). Effects of prenatal stress on fetal and child development: a critical literature review. Neuroscience \& Biobehavioral Reviews, 43, 137-162. DOI

Hepper, P. (2015). Behavior during the prenatal period: Adaptive for development and survival. Child Development Perspectives, 9(1), 38-43. DOI

Liu, D., Diorio, J., Tannenbaum, B., Caldji, C., Francis, D., Freedman, A., Sharma, S., Pearson, D., Plotsky, P. \& Meaney, M. J. (1997). Maternal care, hippocampal glucocorticoid receptors, and hypothalamic-pituitary-adrenal responses to stress. Science, 277(5332), 1659-1662. DOI

Lucci, T. K., Otta, E., David, V. F., \& Chelini, M. O. M. (2016). Maternal depression and offspring's cortisol concentrations in a Brazilian sample. Psico, 47(2), 140-147. DOI

Marx, V., \& Nagy, E. (2015). Fetal behavioural responses to maternal voice and touch. PloS one, 10(6), e0129118. DOI

Murray, L., Stanley, C., Hooper, R., King, F., \& Fiori-Cowley, A. (1996). The role of infant factors in postnatal depression and mother-infant interactions. Developmental Medicine \& Child Neurology, 38(2), 109-119. DOI

Meaney, M. J. (2010). Epigenetics and the Biological Definition of Gene x Environment Interactions. Child development, 81(1), 41-79. DOI

Morais, M. L. S., Lucci, T. K., \& Otta, E. (2013). Postpartum depression and child development in first year of life. Estudos de Psicologia (Campinas), 30(1), 7-17. DOI

O'donnell, K. J., Glover, V., Barker, E. D., \& O'Connor, T. G. (2014). The persisting effect of maternal mood in pregnancy on childhood psychopathology. Development and Psychopathology, 26(2), 393-403. DOI

Ottinger, D. R., \& Simmons, J. E. (1964). Behavior of human neonates and prenatal maternal anxiety. Psychological Reports, 14(2), 391-394. DOI

Parke, R. D. (1972). Mother-Father-Newborn Interaction: Effects of Maternal Medication, Labor, and Sex of Infant. Retrieved from: https://files.eric.ed.gov/fulltext/ ED072840.pdf 
Parke, R. D., Grossmann, K., \& Tinsley, B. R. (1981). Father-mother-infant interaction in the newborn period: A German-American comparison. In T. Field (Ed.), Culture and early interactions (pp. 95-113). Hillsdale, NJ: Lawrence Erlbaum Associates, Inc.

Ribeiro, F. L., Bussab, V. S. R., \& Otta, E. (2004). De colo em colo, de berço em berço. Moura, MLS, organizador. O bebê do século XXI e a psicologia em desenvolvimento. São Paulo: Casa do Psicólogo, 229-74

Rowe-Murray, H. J.,\& Fisher, J. R. (2001). Operative intervention in delivery is associated with compromised early mother-infant interaction. British journal of obstetrics and gynaecology, 108(10), 1068-1075. DOI

Siddiqui, A., \& Hägglöf, B. (2000). Does maternal prenatal attachment predict postnatal mother-infant interaction?. Early Human Development, 59(1), 13-25. DOI

Velandia, M., Matthisen, A. S., Uvnäs-Moberg, K., \& Nissen, E. (2010). Onset of vocal interaction between parents and newborns in skin-to-skin contact immediately after elective cesarean section. Birth, 37(3), 192-201. DOI

Velandia, M., Uvnäs-Moberg, K., \& Nissen, E. (2012). Sex differences in newborn interaction with mother or father during skin-to-skin contact after Caesarean section. Acta Paediatrica, 101(4), 360-367. DOI

Weinberg, M. K., Tronick, E. Z., Cohn, J. F., \& Olson K. L. (1999). Gender differences in emotional expressivity and self-regulation during early infancy. Developmental Psychology, 35(1), 175-188. DOI

Weiss, S. J., Wilson, P., \& Morrison, D. (2004). Maternal tactile stimulation and the neurodevelopment of low birth weight infants. Infancy, 5(1), 85-107. DOI

Widström, A. M., Lilja, G., Aaltomaa-Michalias, P., Dahllöf, A., Lintula, M., \& Nissen, E. (2011). Newborn behaviour to locate the breast when skin-to-skin: a possible method for enabling early self-regulation. Acta paediatrica, 100(1), 79-85. DOI

Zuckerman, B., Bauchner, H., Parker, S., \& Cabral, H. (1990). Maternal depressive symptoms during pregnancy, and newborn irritability. Journal of Developmental and Behavioral Pediatrics. $\underline{\mathrm{DOI}}$ 